Our findings were as follows. There was no significant difference in mean blood glucose concentrations between babies in groups $A$ and $B$ on day 0 . There was no significant difference between the two groups in maternal total proteins, nor in any of the serum protein components. The correlation coefficient between maternal total protein levels, albumin, and globulin components in the mothers in groups $A$ and $B$, and blood glucose in their infants showed no significant difference. The correlation coefficient between maternal serum albumin in group $\mathrm{A}$ and the different categories of babies in the same group (i.e. low birthweight, preterm, and small-for-gestational-age) showed no significant difference. Our findings thus differ from those of Stein, though we are dealing with the same type of population.

M. A. PARENT

Department of Paediatrics, Children's Hospital,

P.O. Box 977, Durban, South Africa.

REFERENCES

Powell, S. J. (1958). The serum protein pattern of liver function tests in the Natal African. South African Fournal of Laboratory and Clinical Medicine, 4, 273.

Stein, H. (1975). Maternal protein depletion and small-for-gestational age babies. Archives of Disease in Childhood, 50, 146.

Dr. H. Stein comments as follows:

I read with great interest the letter of Dr. Parent. There are marked differences between his investigations and ours (Archives, 1975). He has principally investigated the contrast in terms of hypoglycaemia and maternal serum protein levels between term infants (group B) and a group of preterm, low-birthweight, and small-for-gestational-age infants (group A). Even in Group A where he contrasts his 3 categories there is only a relatively small percentage of low-birthweight infants (27 out of 99) and it is not clear whether these are preterm or small-for-gestational-age.

We, on the other hand, investigated a group of low-birthweight infants only, but excluded twins, as we had previously shown that these babies contributed significantly to the high incidence of low-birthweight infants seen by us $(26 \%)$ and especially the small-forgestational-age group (Stein and Ellis, 1974); in the present investigation we were looking for additional aetiological factors. Almost all of our cases were preterm (94 out of 103) and the majority were small-forgestational-age.

It appears that the whole emphasis of the investigations was different. It is also not clear whether Dr. Parent excluded twins as we did. Thus while the population groups are similar, the investigations do not appear comparable.

H. STEIN

Department of Paediatrics, Baragwanath Hospital, P.O. Bertsham 2013, Johannesburg, South Africa. REFERENCE

Stein, H., and Ellis, U. (1974). The low birthweight African baby. Archives of Disease in Childhood, 49, 156.

\section{Opsonic defects}

Sir,

The recently described familial opsonic defect by Scott et al. (1975) in the Archives is a beautifully performed study which deserves recognition. The authors have clearly shown a defect in serum opsonic activity throughout four generations of a family. Their suggestion, however, that, 'A diagnosis of Miller's opsonizing defect was confirmed by demonstration of defective opsonization for yeast phagocytosis by her serum and that of her relatives', is a premise with which I do not fully agree.

Most, if not all, opsonic assays depend upon a multiplicity of plasma factors. While Baker's yeast particles are unique in their dependency upon the fifth component of complement (C5) (Miller and Nilsson, 1974), C5 alone is not sufficient for complete opsonization of yeast. In other words, a deficiency in the yeast opsonic assay may reflect any one of a number of factors, including C5. In order to establish a diagnosis of $\mathrm{C} 5$ dysfunction it is therefore necessary to perform appropriate reconstitution experiments using purified human C5 (Miller and Koblenzer, 1972). Illustration of this point is provided by the observations that patients with other opsonic defects, as for example the patient of Alper and Rosen (1975) with hypercatabolism of C3, have abnormal yeast opsonic assays.

I agree that the nature of any defect revealed, solely, by abnormal yeast opsonic activity requires further definition. In the family reported by us, however, substantial evidence has been presented which points to a functional defect of the $\mathrm{C} 5$ molecule as the cause of the opsonic defect (Nilsson, Miller, and Wyman, 1974). The alternate pathway of complement in this family is normal.

The importance of studies such as that of Scott and co-workers is re-emphasized. A number of opsonic defects obviously exist and the full characterization of each should be vigorously pursued. Not only do we learn much of the normal inflammatory response from each of these defects, but the promise of specific therapy by improved characterization of each is great.

MICHAEL E. MILLER Department of Paediatrics, Charles R. Drew Postgraduate Medical School and U.C.L.A. School of Medicine, 1621 E. 120 th Street, Los Angeles, California 90059

REFERENCES

Alper, C. A., and Rosen, F. S. (1975). Increased susceptibility to infection in patients with defects affecting C3. Immunodeficiency in Man and Animals, p. 302. Ed. by R. A. Good and J. Finstad. Sinauer Associates, Sunderland, Mass.

Miller, M. E., and Koblenzer, P. J. (1972). Leiner's disease and deficiency of C5. Fournal of Pediatrics, 80, 879.

Miller, M. E., and Nilsson, U. R. (1974). A major role of the fifth component of complement (C5) in the opsonization of yeast particles. Partial dichotomy of function and immunochemical measurement. Clinical Immunology and Immunopathology, 2 , 246. 